\title{
Productivity and residual benefits of grain legumes to sorghum under semi-arid conditions in south-western Zimbabwe: Unravelling the effects of water and nitrogen using a simulation model
}

\author{
Bongani Ncube ${ }^{\mathrm{a}, \mathrm{b}, *}$, John P. Dimes ${ }^{\mathrm{b}}$, Mark T. van Wijk ${ }^{\mathrm{b}}$, Steve J. Twomlow ${ }^{\mathrm{b}}$, Ken E. Giller ${ }^{\mathrm{b}}$ \\ a International Crops Research Institute for the Semi-arid Tropics (ICRISAT), PO Box 776, Bulawayo, Zimbabwe \\ ${ }^{\mathrm{b}}$ Plant Productions Systems, Department of Plant Sciences, Wageningen University, 6700 AK, Box 430, Wageningen, The Netherlands
}

\section{A R T I C L E I N F O}

\section{Article history:}

Received 21 December 2007

Received in revised form 31 July 2008

Accepted 5 August 2008

\section{Keywords:}

APSIM

Nitrogen uptake

$\mathrm{N}_{2}$-fixation

Stress factors

\begin{abstract}
A B S T R A C T
The APSIM model was used to assess the impact of legumes on sorghum grown in rotation in a nutrientlimited system under dry conditions in south-western Zimbabwe. An experiment was conducted at Lucydale, Matopos Research Station, between 2002 and 2005. The model was used to simulate soil and plant responses in the experiment. Sequences of cowpea (Vigna unguiculata), pigeonpea (Cajanus cajan), groundnut (Arachis hypogaea) and sorghum (Sorghum bicolor) were used in the rotations. Legumes accumulated up to $130 \mathrm{~kg}$ of $\mathrm{N} \mathrm{ha}^{-1}$ which was potentially available for uptake by sorghum in the following season. The APSIM model predicted total biomass, grain and $\mathrm{N}$ yields of the legume phase within the experimental error and performed well in predicting sorghum yield and $\mathrm{N}$ supplied in the rotation after cowpea and groundnut. The model generally under-predicted sorghum total biomass and grain yield after pigeonpea. Observed patterns of crop water use, evaporative losses during the dry season and re-charge of soil profile at the start of the rainy season were generally well predicted by the model. An assessment of output on sorghum $\mathrm{N}$ and water stresses in the rotation indicated that the legume-cereal rotation is more driven by soil nitrogen availability than water availability even under semi-arid conditions. Further legume-cereal rotation analysis using the model will assist in the understanding of other processes in the rotations in dry environments.
\end{abstract}

(c) 2008 Elsevier B.V. All rights reserved.

\section{Introduction}

The potential contribution of grain legumes to the crop production systems of smallholder subsistence farmers in semiarid regions of Southern Africa is largely unknown. Grain legumes are currently grown over small areas and contribute only to subsistence needs in the smallholder farming systems of Zimbabwe (Mapfumo and Giller, 2001; Rowe and Giller, 2003; Twomlow, 2004). This is also generally true for other countries in southern Africa, such as Botswana, Malawi and Zambia. The scarcity of legumes in semi-arid regions is worsened by the preferential production of cereal staples such as maize and sorghum and uncertain low rainfall. Other reasons for the low production of legumes in Zimbabwe include lack of quality seed, labour and disease constraints, and lack of output markets, so households produce primarily for home consumption (Hilder-

\footnotetext{
* Corresponding author. Current address: WaterNet, PO Box MP 600, Mount Pleasant, Harare, Zimbabwe. Tel.: +263 4 333248/6725; fax: +2634336740.

E-mail addresses: bncube@waternetonline.org, bongisto@yahoo.com (B. Ncube).
}

brand, 1996). There is a critical need to find ways to establish and increase the area of legumes in the cereal-based cropping systems (Mapfumo and Giller, 2001; Twomlow, 2004).

$\mathrm{N}_{2}$-fixing legumes can have a positive impact on soil fertility by enhancing nitrogen availability and therefore benefiting a cereal crop grown in the subsequent season (Armstrong et al., 1999; Sanginga, 2003). There is need to study such crop sequences under semi-arid conditions in order to get a clear understanding of the rotations and the extent of residual benefits that legumes can provide to subsequent cereals. Such knowledge will show whether research should focus on increasing nitrogen availability or on other aspects such as water management in the dry environments. It is difficult to clearly unravel such information using field experimentation over 2 or 3 years only (Ncube et al., 2007). The use of relevant crop-soil models can assist in providing answers to these questions.

Many crop-soil models have been used under different conditions to create a better understanding of plant-soil interactions. Models such as the Decision Support System for Agrotechnology Transfer (DSSAT) and the Erosion Productivity Impact Calculator (EPIC) are examples of models that have been used to 
simulate growth and development of crops (Tsuji et al., 1994; Williams et al., 1990). The Agricultural Production Systems Simulator (APSIM) model is a well-tested model that provides reasonably accurate predictions of crop production in relation to climate, genotype, soil and management factors, while addressing long-term resource management issues in farming systems (McCown et al., 1996). APSIM is considered to be one of the most appropriate models for use in tropical soil and crop management (Delve and Probert, 2004). The model is useful in capturing the interactions between climatic conditions, soil types and nutrient dynamics in cereal-based farming systems in Africa and Australia (Whitbread et al., 2004). The APSIM framework is well documented and described, and has been tested with observed data under a wide range of conditions (Keating et al., 2003). Performance in Africa has also been reported: simulating $\mathrm{N}$ dynamics of manure inputs (Delve and Probert, 2004), maize response to N (Shamudzarira and Robertson, 2002), legumes in Malawi (Robertson et al., 2005), weed competition (Keating et al., 1999; Dimes et al., 2002) and water use efficiency (Dimes and Malherbe, 2006) in smallholder farming systems.

Most published work done in Africa has looked at single crop sequences. Another gap in previous APSIM applications in Africa has been the limited application of the legume modules in dry areas, and seldom, if ever, assessment of model performance for simultaneous above- and below-ground dynamics, in this case soil water, $\mathrm{N}$ uptake and $\mathrm{N}_{2}$-fixation, biomass production and partitioning to grain. We used APSIM to assist in explaining our experimental results on the residual effects of grain legumes on growth and yield of sorghum under semi-arid conditions in Zimbabwe. Our objectives were first, to analyse if the APSIM model was capable of modelling the growth and yield of grain legumes and the residual effects of the grain legumes on sorghum yield; and second, to use the model to analyse the nitrogen and water stress dynamics in the legume-cereal rotation and to quantify when each of the two factors was limiting in grain production, and hence unravel their effects.

\section{Materials and methods}

\subsection{Summary of the field experiment}

Experiments were carried out at the Matopos Research Station $\left(28^{\circ} 30^{\prime} \mathrm{E}, 20^{\circ} 23^{\prime} \mathrm{S}\right)$ Zimbabwe, at the Lucydale experiment site. The experiments were carried out over three cropping seasons 2002/ 2003 (314 mm rainfall), 2003/2004 (650 mm rainfall) and 2004/ 2005 (301 mm rainfall). Details of the experimental design and management are given in Ncube et al. (2007). Legume phase experiments (Experiment 1, Experiment 2 and Experiment 3) were established in each season at different sites in two adjoining fields. The legume phase is the first phase of the rotation experiment and it included a sorghum plot as a control treatment for the purposes of determining $\mathrm{N}$-fixation by the difference method and for assessing the enhanced nitrogen supply following the legume crops. Two varieties of groundnut (Arachis hypogaea L.), Nyanda and Natal Common, two of cowpea (Vigna unguiculata (L.) Walp), CBC1 and 86D 719, two of pigeonpea (Cajanus cajan (L.) Millsp.), ICPL 87091 and ICEAP 00535 and medium duration sorghum (Sorghum bicolor (L.) Moench), SV4, were planted following recommended plant spacing in $20 \mathrm{~m} \times 10 \mathrm{~m}$ plots. All plots in legume and sorghum phases received a basal application of $P$ fertiliser $\left(20 \mathrm{~kg} \mathrm{P} \mathrm{ha}^{-1}\right)$. At harvest, grain and stover samples were collected and dried in the oven at $70{ }^{\circ} \mathrm{C}$ to determine yield components. Further, the samples were ground and analysed for $\% \mathrm{~N}$ and ${ }^{15} \mathrm{~N}$ using a $20-20$ stable isotope mass spectrophotometer. $\mathrm{N}_{2}$-fixation was determined using the ${ }^{15} \mathrm{~N}$ natural abundance method (Boddey et al., 2000) and the N Difference Method (Giller, 2001). At the end of each legume phase the plots were split into two $10 \mathrm{~m} \times 10 \mathrm{~m}$ sub-plots. In one sub-plot the above-ground harvested residues were removed, while in the other sub-plot the residues were incorporated. In the following season(s) a sorghum crop was planted in all plots. At harvest of the sorghum phase all crop residues were removed. At the end of experimentation there were three legume phases, two legume-sorghum phases and one legume-sorghum-sorghum phase.

Soil water was measured using a Wallingford neutron probe (Bell, 1987), and the gravimetric method during both the legume and the sorghum phases. Soil water was measured in Experiment 1 and 2 on a weekly basis during the crop period and less often during the dry season. There was a measurement gap in the 2003/ 2004 cropping season due to probe malfunction. Soil depth across experimental areas was highly variable $(35-90 \mathrm{~cm}$, average of 68 and $70 \mathrm{~cm}$ for Experiment 1 and 2, respectively). While there were sufficient measurements to estimate soil water parameters for model input to $70 \mathrm{~cm}$, total soil water in the $0-35 \mathrm{~cm}$ zone was used to evaluate predictions of soil water dynamics since this zone was better represented across treatments and time.

\subsection{Set-up of the model}

\subsubsection{Soil water and soil characteristics}

Two soil water descriptions were used to simulate the water balance for the three experimental sites (Fig. 1). The plant available water capacity (PAWC) for Experiment 1 soil was $59 \mathrm{~mm}(0-$ $65 \mathrm{~cm})$; and Experiment 2 soil was $53 \mathrm{~mm}(0-70 \mathrm{~cm})$. The values for Experiment 2 were used in Experiment 3 since the fields were
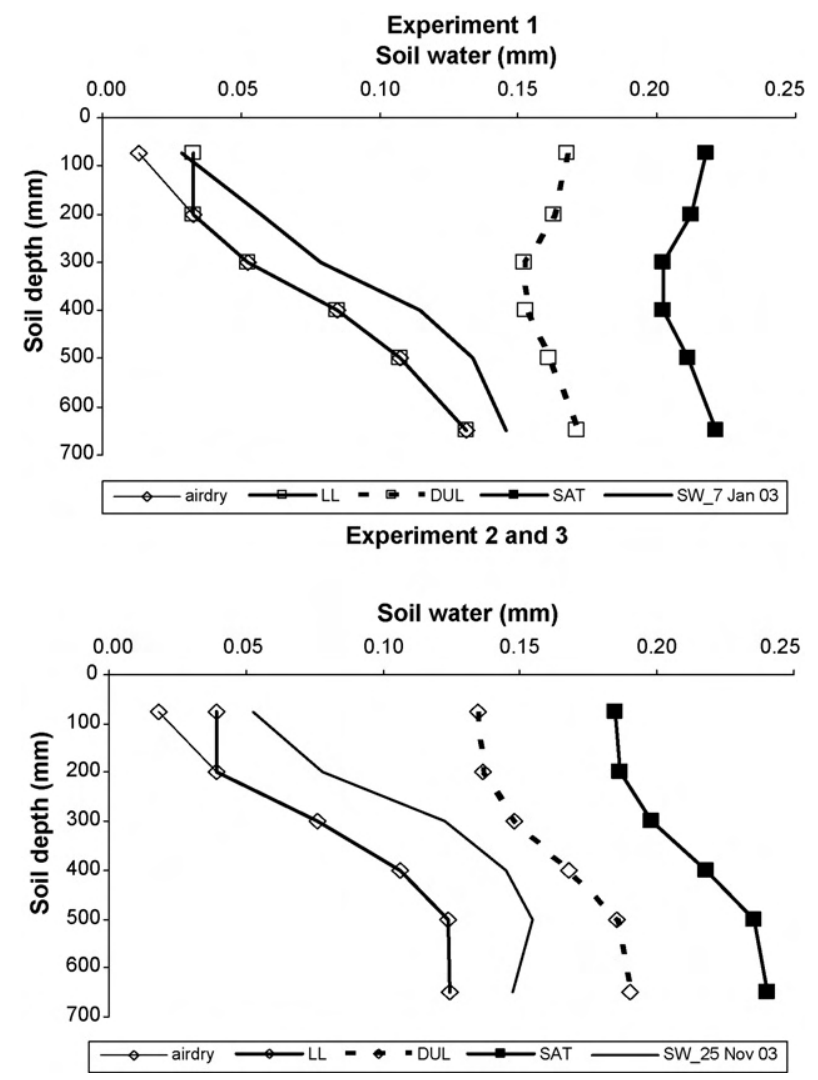

Fig. 1. Soil water parameters for the two soils at Lucydale. LL stands for lower limit, DUL for the drained upper limit or field capacity, SAT stands for the saturated profile and SW_7jan03 and SW_25nov03 stand for the measured soil water profile on the 7 th of January and the 25th November 2003, respectively. 
Table 1

Soil organic carbon used to initialise the three Lucydale soils in APSIM and nitrate-N values used to update the model on measured dates ${ }^{\text {a }}$ (see text)

\begin{tabular}{|c|c|c|c|c|c|c|c|}
\hline \multirow{2}{*}{$\begin{array}{l}\text { Depth } \\
\text { (cm) }\end{array}$} & \multirow{2}{*}{$\begin{array}{l}\mathrm{BD} \\
\left(\mathrm{g} \mathrm{cm}^{-3}\right)\end{array}$} & \multicolumn{3}{|c|}{$\mathrm{NO}_{3}-\mathrm{N}(\mathrm{ppm})$} & \multicolumn{3}{|l|}{ OC (\%) } \\
\hline & & Expt. 1 & Expt. 2 & Expt. 3 & Expt. 1 & Expt. 2 & Expt. 3 \\
\hline $0-15$ & 1.66 & 6.10 & 3.51 & 1.41 & 0.79 & 0.42 & 0.42 \\
\hline $15-25$ & 1.63 & 5.41 & 3.51 & 1.41 & 0.75 & 0.42 & 0.42 \\
\hline $25-35$ & 1.60 & 3.26 & $1.93^{\mathrm{b}}$ & $0.77^{b}$ & 0.67 & $0.37^{b}$ & $0.37^{b}$ \\
\hline $35-45$ & 1.55 & 1.12 & $0.78^{\mathrm{b}}$ & $0.31^{\mathrm{b}}$ & 0.58 & $0.32^{\mathrm{b}}$ & $0.32^{\mathrm{b}}$ \\
\hline $45-55$ & 1.50 & 1.12 & $0.78^{\mathrm{b}}$ & $0.31^{\mathrm{b}}$ & 0.58 & $0.32^{\mathrm{b}}$ & $0.32^{\mathrm{b}}$ \\
\hline $55-70$ & 1.45 & 0.96 & $0.60^{\mathrm{b}}$ & $0.24^{b}$ & 0.44 & $0.24^{\mathrm{b}}$ & $0.24^{\mathrm{b}}$ \\
\hline
\end{tabular}

${ }^{\text {a }} \mathrm{NO}_{3}$-N sampling dates-Experiment 1: 16 December 2002, Experiments 2 and 3: 25 November 2003, 2004.

b Not measured, values derived from measured surface layer values and normalised distribution of Experiment 1 data.

adjoining with very similar characteristics. Evaporation and runoff coefficients were selected to reflect a tropical environment and the crusting characteristics of the Lucydale soils. For each soil, the first and second stage evaporation coefficients were set at $1 \mathrm{~mm}$ and $6 \mathrm{~mm} \mathrm{day}^{-1 / 2}$ (Ritchie, 1972) and the runoff curve number for bare soil (Williams and LaSeur, 1976) was set at 90.

Three separate soil descriptions were used with APSIM to simulate the nitrogen balance of each experiment. Table 1 shows the nitrate- $\mathrm{N}$, organic carbon and bulk density used in modelling the three experiments. The soil $\mathrm{C}: \mathrm{N}$ ratio for all soils was set at 15 .

\subsubsection{Management and climate}

The model was set-up to run with daily climate inputs from the 1st of November 2002 to the 30th of June 2005. Actual rainfall data measured at Lucydale was used. Temperature and radiation data were obtained from the Meteorological Office climate records at Matopos Research Station (approximately $5 \mathrm{~km}$ apart). Simulation of the legume phase experiments was initialised on the 1 st of November each year, with soil water in each layer set to the crop lower limit and available mineral $\mathrm{N}$ $\left(\mathrm{NO}_{3}+\mathrm{NH}_{4}-\mathrm{N}\right)$ set to a small amount $\left(12 \mathrm{~kg} \mathrm{~N} \mathrm{ha}^{-1}, 0-70 \mathrm{~cm}\right)$, and surface organic matter set to zero. Soil nitrate-N and soil water in each layer was subsequently updated on the date of the first observed values in each legume phase experiment (Fig. 1 and Table 1). Simulation of the legume-sorghum rotation was continuous from the November 1 starting date for each experiment.

Crop management was specified in a manner consistent with the experimental procedures. Sowing dates for the legume and sorghum crops in Experiment 1 were 19 December in 2002, 3 December in 2003 and 14 December in 2004. For Experiment 2 the sowing dates were 4 December in 2003 and 13 December in 2004, while the Experiment 3 sowing date was 12 December 2004. Dates of legume residue incorporation were: 23rd October 2003 in Experiment 1, and 27 July 2004 in Experiment 2. The amount of residues, the $\mathrm{N}$ content and the $\mathrm{C}: \mathrm{N}$ ratio of incorporated material have been specified in Table 5 of Ncube et al., 2007. Plant populations were measured in 2002/2003 season only and these were used as inputs to the model to simulate the Experiment 1 legume phase crops. The observed plant population for each variety was: $\mathrm{CBC} 1=11.3$ plants $\mathrm{m}^{-2}, 86 \mathrm{D} \quad 719=12$ plants $\mathrm{m}^{-2}$ (high cowpea populations because no thinning operation), ICEAP $\quad 00535=8$ plants $\mathrm{m}^{-2}, \quad$ ICPL $\quad 87091=6.3$ plants $\mathrm{m}^{-2}$, Natal Common $=8.3$ plants $\mathrm{m}^{-2}$, Nyanda $=5.7$ plants $\mathrm{m}^{-2}$ and $\mathrm{SV} 4=6.3$ plants $\mathrm{m}^{-2}$. The measured pigeonpea and groundnut populations were substantially below the target populations for these two crops $\left(10\right.$ and 11 plants $\left.\mathrm{m}^{-2}\right)$. Accordingly, the pigeonpea (ICEAP 00535 and ICPL 87091) and groundnut (Natal
Common and Nyanda) cultivars for Experiments 2 and 3 were simulated using the average of the population observed for the first season (pigeonpea $=7$ plants $\mathrm{m}^{-2}$, groundnut $=7$ plants $\mathrm{m}^{-2}$ ), while the cowpea cultivars were simulated using the target population ( 6.6 plants $\mathrm{m}^{-2}$ ). In 2003/2004, rotation sorghum crops in Experiment 1 were simulated using a population of 2 plants $\mathrm{m}^{-2}$ to reflect the observed poor establishment of sorghum in that season. Sorghum was simulated using a population of 4 plants $\mathrm{m}^{-2}$ in the Experiment 3 legume phase and in all rotation crops in 2004/ 2005.

\subsubsection{Crop parameters}

Simulation of observed phenology and grain partitioning of the experimental cultivars for cowpea (CBC1 and 86D 719), pigeonpea (ICEAP 00535 and ICPL 87091) and sorghum (SV4), was found to be adequate by selecting from existing cultivar descriptions in APSIM. Hence, APSIM crop parameters for 'Banjo' and 'Red-Caloona' cowpea, 'short-duration' pigeonpea and 'early' sorghum were selected to describe CBC1 and 86D 719 cowpeas, both ICEAP 00535 and ICPL 87091 pigeonpea and SV4 sorghum, respectively. In the case of groundnut, new cultivar parameters were constructed for Natal Common and Nyanda from existing APSIM cultivars ('McCubbin' and 'Chico') based on approaches set out by van Keulen and Seligman (1987). The thermal time from initiation to flowering and the harvest index (HI) increase parameter for each cultivar was calibrated to approximately simulate the respective average observed flowering date and harvest index, across the three seasons.

The simulation of plant nitrogen relations in APSIM was via the three processes that are defined within the model. Uptake can be via mass flow where soil $\mathrm{N}$ is passively taken up by plants. The second mechanism is through active (energy-spending) uptake that plants employ to extract nitrate from the root zone. When passive and active uptake cannot satisfy plant demand legumes would then fix nitrogen.

Cowpea yields in 2003/2004 (Experiment 2) were severely constrained by aphids. In this case, the simulated plant population was manipulated to generate the observed low biomass production. This was deemed necessary in order to more adequately test simulation of the observed $\mathrm{N}_{2}$-fixation and residual $\mathrm{N}$ effects on the subsequent sorghum yield. Similarly, the SV4 treatment in Experiment 2 had poor crop establishment and produced no grain in $2003 / 2004$. It was simulated with a low plant population $\left(0.5\right.$ plants $\left.\mathrm{m}^{-2}\right)$ to simulate some biomass and $\mathrm{N}$ uptake in this season and thereby, a lower residual $\mathrm{N}$ supply to the following sorghum in 2004/2005.

\subsection{Reporting and data analysis}

The model was set to report all selected data on a daily basis. Total biomass and grain yield were reported on a dry weight basis ( $0 \%$ moisture content). Elsewhere, Genstat 8.1 was used to analyse observed total biomass and grain yield for both legumes and sorghum (Ncube et al., 2007). The root mean square deviation (RMSD) values were calculated for the comparisons of all observed and predicted data. The RMSD is the weighted difference between predicted and observed. The formula for the calculation is shown by the following equation:

$\operatorname{RMSD}=\sqrt{\frac{1}{n} \sum_{i=1}^{n}\left(x_{i}-y_{i}\right)^{2}}$

where $x$ is the simulated yield and $y$ is the measured yield, and $n$ is the number of observations (Kobayashi and Salam, 2000). 


\section{Results and discussion}

In this study the model was used to predict total biomass and grain yields of legume crops across three seasons, and to predict grain yield of sorghum grown in rotation. We assessed the performance of APSIM in analysing observed responses of the legume-cereal rotations. Simulation of soil water balance under various legumes and sorghum crops across years was also evaluated. Finally the model was used to explore nitrogen and water stress dynamics within the legume-cereal rotation. Elsewhere, APSIM has been tested extensively in Australia to predict yields of sorghum, forage, pasture and grain legumes (Hammer et al., 2001; Robertson et al., 2002; Probert et al., 1998, 2005; Whitbread and Clem, 2006; Hill et al., 2006). APSIM has also been tested on pigeonpea extra-short, short and medium duration varieties in India (Robertson et al., 2001). There are no reported studies evaluating APSIM predictions of groundnut, pigeonpea and cowpea or sorghum rotations in semi-arid Southern Africa. Our discussion therefore centres on explaining the additional under- standing that comes from using a simulation model and qualifying APSIM's performance in conjunction with experimental data to study the dynamics of a complex cropping system such as legumecereal rotations in a highly variable rainfall environment.

\subsection{Soil water}

Simulation of soil water use by legumes and sorghum crops in the $0-0.35 \mathrm{~m}$ soil layer was generally good for the wet and dry cropping seasons in the two experiments (Fig. 2). As there were no statistically significant differences between treatments in measured soil water profiles in Experiment 1, we have included the measured soil water for the SV4 plots only, and the predicted soil water for a subset of the simulated treatments.

For the legume phase in Experiment 1, there was very little difference in predicted water use patterns between the legumes and sorghum, except for the pigeonpea treatment which had the lowest total biomass growth and therefore the least water demand in the early stages of growth. In general, the predicted water use

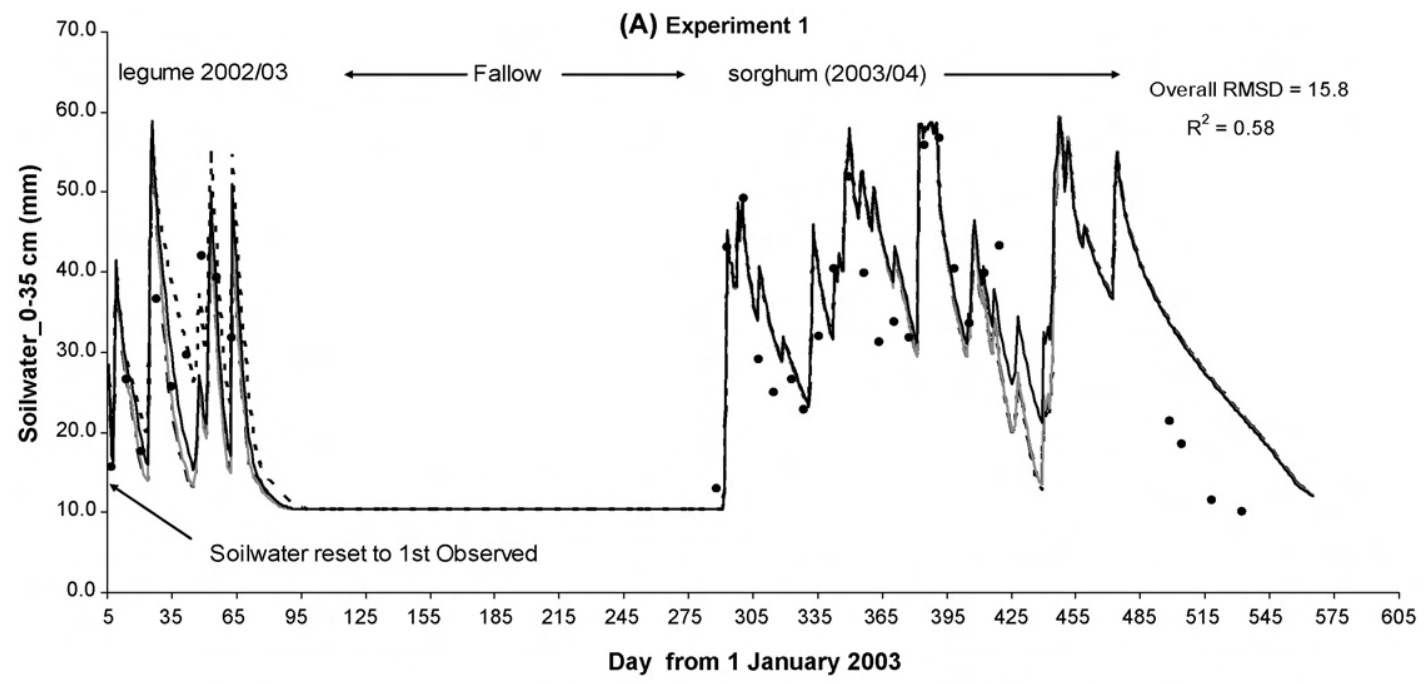

-. - Pred_ICEAP 00535 - - Pred_86D 719 —Pred_Natal Common — Pred_sorghum • Obs_sorghum

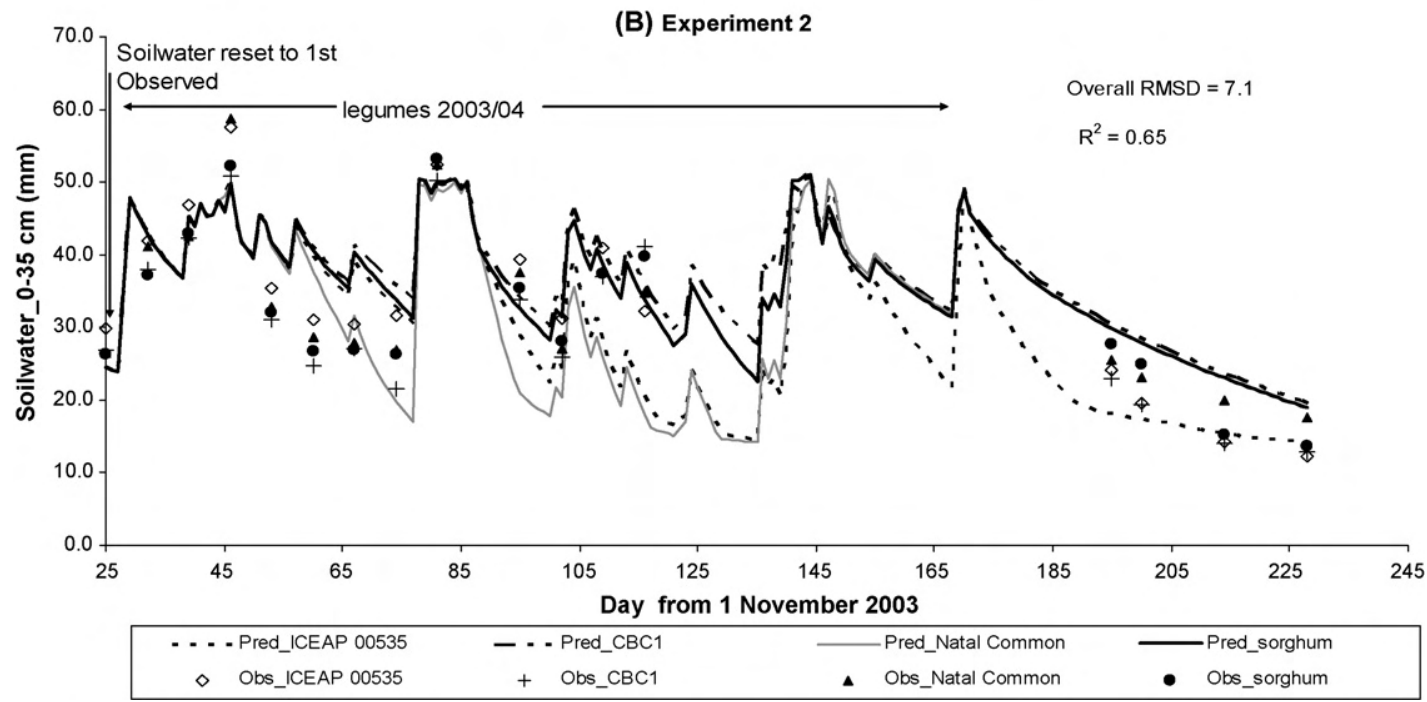

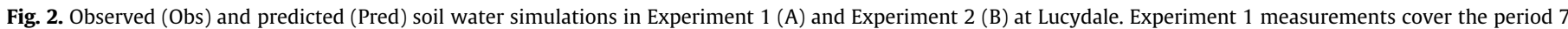

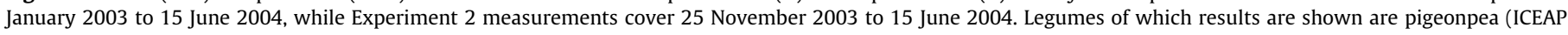
00535), cowpea (CBC1) and groundnut (Natal Common). 
patterns were similar to those observed for sorghum. The reason for lack of difference in model predictions between legumes and the sorghum is due to the high $\mathrm{NO}_{3}-\mathrm{N}$ availability ( $39 \mathrm{~kg} \mathrm{~N} \mathrm{ha}^{-1}$ ) at the start of this experiment, meaning that the sorghum growth was not overly $\mathrm{N}$ stressed relative to the legumes and had similar demand and uptake of available moisture in this low rainfall season.

For the wet 2003/2004 season, soil water in Experiment 1 was predicted well in the period preceding sorghum planting (day 275335 ). In the subsequent cropping period there was no difference in predicted water use patterns for the sorghum crops following the legume phase treatments, except for sorghum following sorghum between day 425 and 455 which had less predicted water use than sorghum following legumes. In the model, this simulated difference in water use is a consequence of the lower $\mathrm{N}$ supply, less total biomass production and therefore less water demand compared with sorghum following the legumes.

In Experiment 2, there were more obvious differences between the observed water use patterns of the legume and sorghum treatments, albeit with some inconsistencies. For example, the observed soil water for this experiment in Fig. 2B shows there is substantial drying of the profile for all treatments from day 45 to 65 when the crop is in the early growth phase following planting on day 35 . Whereas, during the relatively dry February period (day 93-120) when the crops are approaching full vegetative growth, there is much less evidence of soil drying. Consequently there are some large discrepancies between the observed and predicted soil water in Experiment 2.

In the early vegetative phase, the predicted water use by groundnut far exceeded that of sorghum, cowpea and pigeonpea (but within the extent of the observed data). The lower predicted water use by these three crops corresponds to their lower total biomass production at this time. In the subsequent period (day 85145), the simulated water use by sorghum and cowpea is much less than that of pigeonpea and groundnut, both of which had higher total biomass production than the former. By day 150, the simulated sorghum, cowpea and groundnut had reached maturity; hence we see only pigeonpea continuing to use soil water beyond this point. However, the simulated maturity date for the pigeonpea (day 204) is 22 days later than when the actual field crop was harvested, suggesting that the crop growth parameters describing the phenology and/or the stress functions affecting phenology of the pigeonpea cultivar need improvement.

Good prediction of soil water re-charge in the pre-sowing period in 2003/2004 season and the dry down of the soil profile by the crop during grain-filling and into the dry season by soil evaporation was evident for this semi-arid environment. However, over-prediction of observed soil water post-harvest indicated the need to consider weed growth in simulating the water (and by implication $\mathrm{N}$ ) balance of sequential cropping systems. The importance of adequate simulation of crop phenology, and thereby crop duration, in simulating the soil water balance was also highlighted in the case of pigeonpea.

\subsection{Simulation of crop yields in the legume phase}

\subsubsection{Phenology, total biomass and grain}

Days to 50\% flowering were measured in Experiment 1 and 3. No data were collected for sorghum in Experiment 3. In the case of groundnut, cultivar parameters were constructed and calibrated using the observed flowering data. Otherwise, results in Fig. 3 show that the phenology of the pigeonpea, cowpea and sorghum cultivars used in this experiment were adequately described by selecting from existing cultivar parameters in APSIM, although pigeonpea flowering was predicted to be substantially longer than
(A) Experiment 1

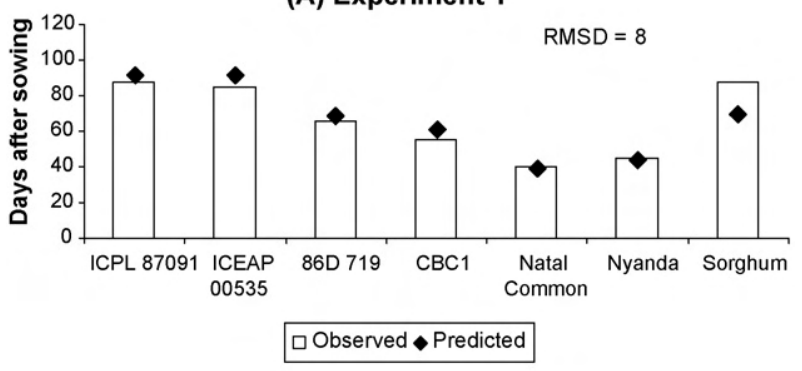

(B) Experiment 3

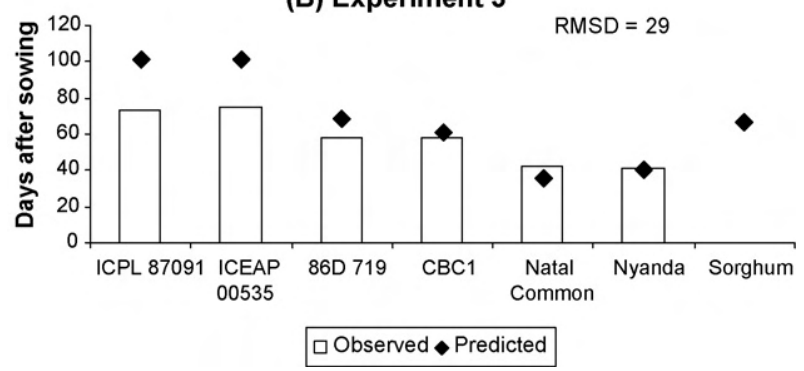

Fig. 3. Observed and predicted flowering (50\%) days after sowing (das) in Experiment 1 (2002/2003) (A) and Experiment 3 (2004/2005) (B) at Lucydale. No data available for sorghum in (B).

observed in Experiment 3, where it was observed to be 15 days shorter than that in Experiment 1.

As observed above (Fig. 2) simulation of the pigeonpea vegetative stage was predicted to be longer than observed in some instances with consequences for the simulation of the soil water balance. Also, the groundnut cultivar growth coefficients calibrated in this study are specific to the results and conditions of this experiment. Studies are therefore required to determine the growth and phenology parameters under controlled, non-stress conditions for proper parameterisation of the African cultivars of these legumes.

The model generally showed good prediction of total biomass and grain yields of the legumes in all three cropping seasons (Fig. 4), providing evidence that APSIM captured the effects of variable water supply on crop production in very wet and very dry seasons quite well. The equally good performance in total biomass $\left(\right.$ RMSD $\left.=643 \mathrm{~kg} \mathrm{ha}^{-1}, R^{2}=0.65\right)$ and grain $\left(\mathrm{RMSD}=221, R^{2}=0.79\right)$ prediction is also indicative that total biomass accumulation and partitioning to grain is generally well simulated by the legume and sorghum crop modules under these range of conditions. The main exception was an under-prediction in total biomass for Nyanda groundnut, and over-prediction of its grain yield, in the 2002/2003 season.

Prediction of total biomass (TBM) and grain yield of sorghum in both Experiments 1 and 3 was very close to the observed yields (Fig. 4). The simulated cowpea and sorghum yields in 2003/2004 were influenced by modification of the plant population to capture effects of aphid damage or poor plant stands on total biomass production observed in these treatments.

\subsubsection{Legume nitrogen uptake}

The predictions for $\mathrm{N}$ uptake by legumes were generally very good (RMSD $=17 \mathrm{~kg} \mathrm{~N} \mathrm{ha}^{-1}$ ) particularly in the 2003/2004 (Expt. 2) and the 2004/2005 (Expt. 3) seasons (Fig. 5). The results suggest that the combined uptake of $\mathrm{N}$ via $\mathrm{N}_{2}$-fixation and soil $\mathrm{N}$ supply was well simulated by the model. As no inorganic fertilisers were applied, the good prediction of sorghum $\mathrm{N}$ uptake in Experiments 1 
Total Biomass

(a) $2002 / 03$

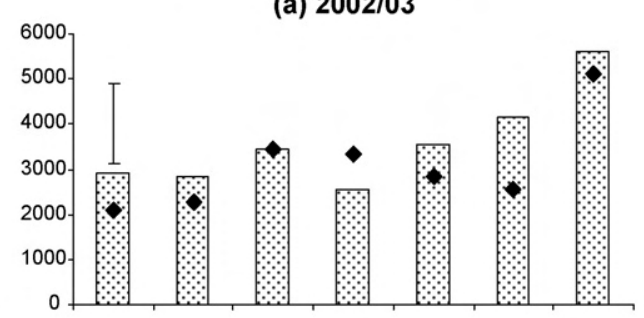

(b) 2003/04

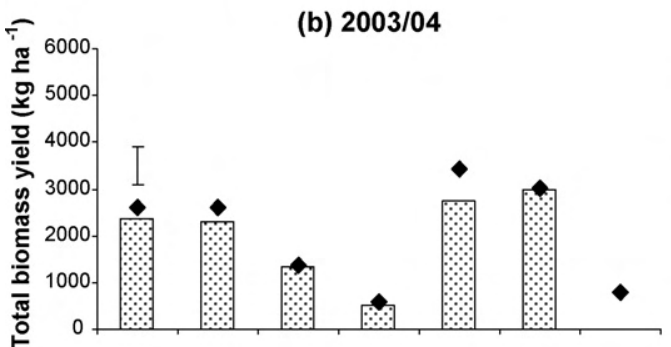

(c) $2004 / 05$

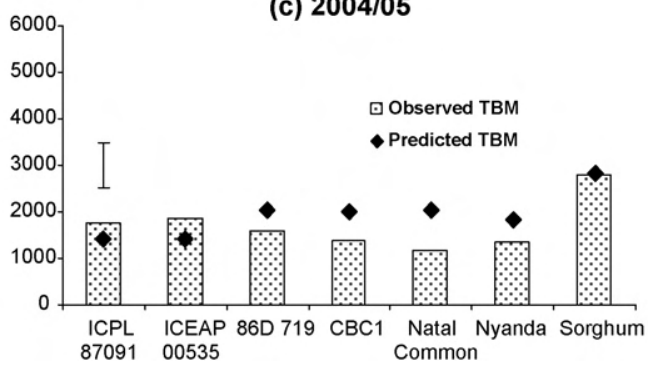

Grain

(a) $2002 / 03$

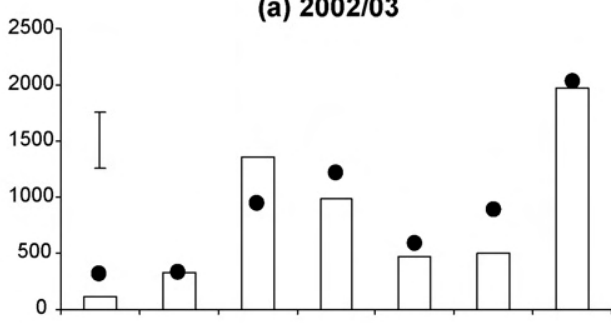

(b) $2003 / 04$

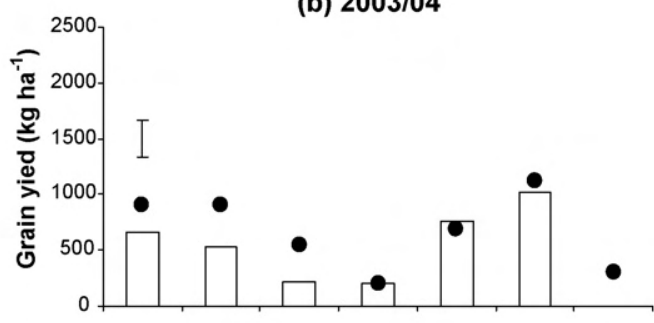

(c) $2004 / 05$

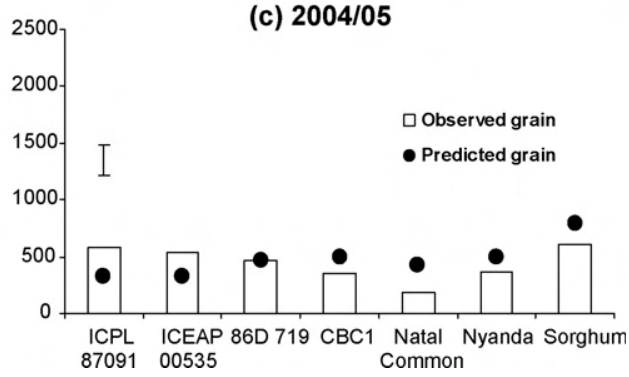

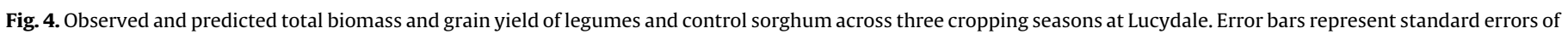

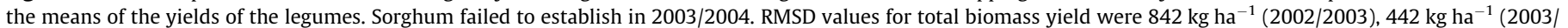
2004) and $545 \mathrm{~kg} \mathrm{ha}^{-1}$ (2004/2005). RMSD values for grain yield were $251 \mathrm{~kg} \mathrm{ha}^{-1}$ (2002/2003), $228 \mathrm{~kg} \mathrm{ha}^{-1}$ (2003/2004) and 168 kg ha ${ }^{-1}$ (2004/2005).

and 3 (Fig. 5) is a strong indicator that the APSIM's routines for mineral N supply from soil organic matter (and sorghum uptake of that $\mathrm{N}$ ) perform well for the soil and sorghum growth conditions of this environment.

However, in Experiment 1, observed $\mathrm{N}$ uptake by legumes in excess of $100 \mathrm{~kg} \mathrm{~N} \mathrm{ha}^{-1}$ was substantially under-predicted by the

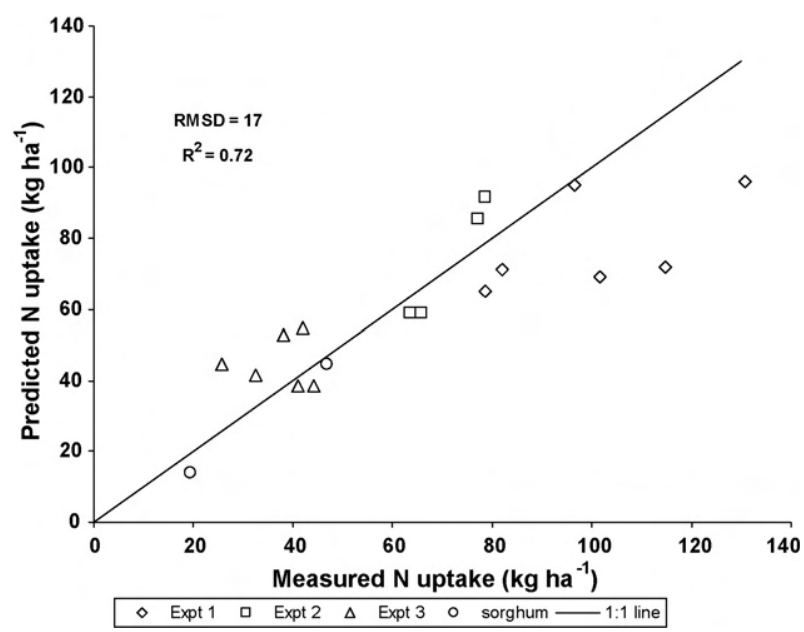

Fig. 5. Plot of observed against predicted legume and sorghum nitrogen uptake across three seasons at Lucydale. Experiment represents the seasons as Experiment 1 (2002/03), Experiment $2(2003 / 04)$ and Experiment $3(2004 / 05)$. The cowpea data is excluded in Experiment 2 due to aphid damage. model. Given the large amount of soil mineral $\mathrm{N}$ at the start of this experiment ( $39 \mathrm{~kg} \mathrm{~N} \mathrm{ha}^{-1}$ ); it is possible that the plant $\mathrm{N}$ coefficients that allow for luxury consumption of $\mathrm{N}$ may need to be adjusted higher. On the other hand, the very high $\mathrm{N}$ concentrations measured in legumes in this season (2.7-3.5\%) were similar to that found in the other two seasons (2.5\% Experiment 2 and 2.0\% in Experiment 3), suggesting that this result may also be an experimental artefact. Nevertheless, good prediction of $\mathrm{N}$ uptake for the cowpea cultivar (97 $\mathrm{kg} \mathrm{N} \mathrm{ha}^{-1}$ ) is largely due to over-prediction of its TBM (Fig. 4), which serves to highlight the value of measuring several plant growth parameters to more rigorously test the accuracy of model predictions.

\subsubsection{Nitrogen fixation}

Ncube et al. (2007) assessed $\mathrm{N}_{2}$-fixation of the legumes in this study using the ${ }^{15} \mathrm{~N}$ natural abundance method and $\mathrm{N}$ difference methods.

In this study, predicted estimates for $\mathrm{N}_{2}$-fixation in aboveground plant materials showed greater disparity with the ${ }^{15} \mathrm{~N}$ natural abundance estimates (RMSD $=22 \mathrm{~kg} \mathrm{~N} \mathrm{ha}^{-1}$ ) than those derived by the difference method (RMSD $16 \mathrm{~kg} \mathrm{~N} \mathrm{ha}^{-1}$, Fig. 6b). However, in relation to the observed total $\mathrm{N}$ uptake (Fig. 5) the lower natural abundance method estimates in this case imply inconceivably high $\mathrm{N}$ supply from soils of quite low soil organic matter content.

In contrast, the difference method explicitly takes the $\mathrm{N}$ supply capacity of the soil into account by using the reference plant (in this case, sorghum) as the bioassay of its supply. In turn, the model simulates the supply of mineral $\mathrm{N}$ to the legume taking into 
(a) $\mathrm{N}_{2}$-Fixation $-{ }^{15} \mathrm{~N}$ natural abundance method

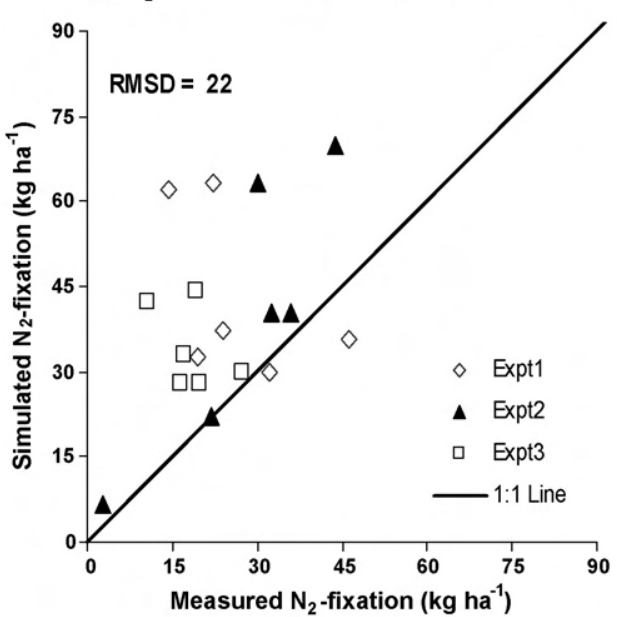

(b) $\mathrm{N}_{2}$-Fixation - Difference method

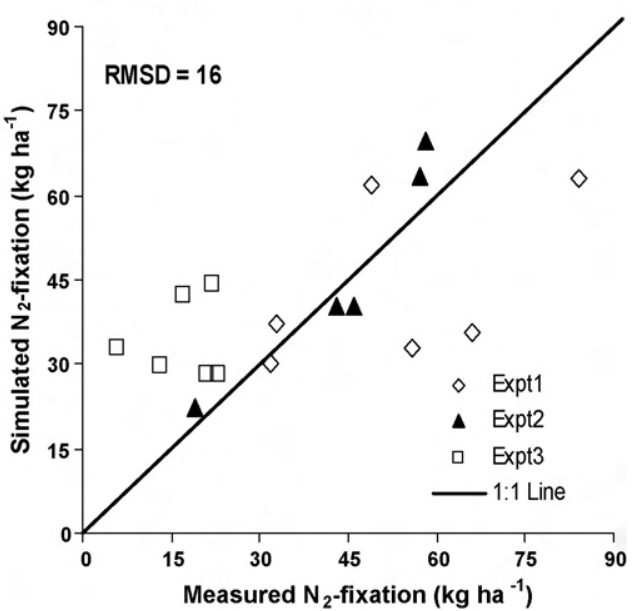

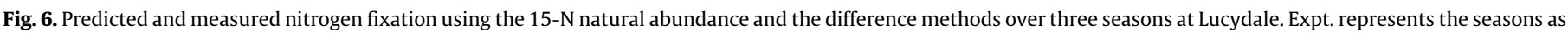
Experiment 1 (2002/2003), Experiment 2 (2003/2004) and Experiment 3 (2004/2005). The cowpea data is excluded in Experiment 2 due to aphid damage.

account the organic $\mathrm{N}$ status of soil layers, its mineralisation of $\mathrm{N}$ in relation to changing water conditions (along with other factors), the presence of roots in a layer and demand of the legume crop for uptake. Hence the model approach is much more aligned to the difference method. The closer agreement with the difference method's $\mathrm{N}_{2}$-fixation estimate is therefore understandable, especially in this case where the model predicted well the $\mathrm{N}$ uptake of the reference sorghum plant (Fig. 5).

However, it is also apparent that more evaluation of the legume modules is warranted. In 2002/2003 season the natural abundance and difference methods were not well correlated as already reported in Ncube et al., 2007. The model gave very good predictions of $\mathrm{N}_{2}$ fixation in the wetter 2003/2004 season, but consistently overpredicted $\mathrm{N}_{2}$-fixation in the drier 2004/2005 season, and that this was accompanied by a general over-prediction of the legume total biomass in this experiment (Fig. 4). The implications are that simulated $\mathrm{N}_{2}$-fixation was not restrained sufficiently in the dry conditions, allowing the excess growth to take place. Hence it is possible that the water-stress relationship for simulating $\mathrm{N}_{2^{-}}$ fixation may need further evaluation and development.

\subsection{Simulation of sorghum yields in rotations}

\subsubsection{Sorghum total biomass and grain yield}

Fig. 7 shows the observed and predicted TBM and grain yield for the first sorghum crop following the legumes phase in Experiment 1 (2003/04) and Experiment 2 (2004/05), with removal and incorporation of the crop residues. For the observed grain yield data, variety treatment means were statistically different only in the $2003 / 2004$ season $(P<0.05)$, and there was no significant differences in grain yield between plots with removal and with incorporation of residues in either season (Ncube et al., 2007).

\subsubsection{Legume-sorghum yields}

In 2003/2004, the model simulated no difference in total biomass or grain yield of sorghum in response to removal and incorporation of the different legume residues (Fig. 7a and c). This is consistent with the statistical analysis of the observed yields (Ncube et al., 2007). For the legume-sorghum rotations, the model generally under-predicted TBM yield of sorghum and consistently over-predicted grain yield (Fig. 7a and c). Hence the model simulated a much higher harvest index $(0.49)$ for sorghum than was observed $(0.30)$ in this wet season, and the simulated TBM, grain yield or $\mathrm{HI}$ was not responsive to additional inputs of $\mathrm{N}$ (as residues) in the legume-sorghum rotation.

In 2004/2005, both observed and predicted TBM and grain yield of sorghum following legumes had smaller yields compared to 2003/2004 (Fig. 7b and d). This reflected the much lower rainfall in 2004/2005, but also the smaller $\mathrm{N}$ inputs (for example, 55$97 \mathrm{~kg} \mathrm{~N} \mathrm{ha}^{-1}$ was returned in the incorporated residues in 2003/ 2004 , compared with $10-47 \mathrm{~kg} \mathrm{~N} \mathrm{ha}^{-1}$ in $\left.2004 / 2005\right)$. For this season, the predicted TBM of sorghum following cowpea and groundnut was in close agreement with the observed yields, while the predicted grain yields were generally close to, but below the observed grain yields. In contrast, predicted TBM and grain yield of sorghum following pigeonpea were substantially less than the observed yields.

One explanation for this is that the model did not simulate any leaf fall for pigeonpea because the detachment parameter is turned off in the released version of APSIM Version 5.1. We tested turning this parameter on such that $50 \%$ of senesced leaf material was detached from the standing plant (and added to surface OM). This improved simulation of the yields in the following sorghum crop, but at the expense of under-predicting the observed total biomass of pigeonpea at the end of the legume phase.

\subsubsection{Sorghum-sorghum yields}

The model simulated a large reduction in both TBM and grain yield with incorporation of sorghum residues compared to its removal for the sorghum-sorghum rotation (Fig. 7). In doing so, the model substantially over-predicted the observed TBM and grain yield of the no residues treatment, while predicting observed yields of the incorporation treatment closely. The simulated HI decreased from 0.5 with removal of residues to 0.4 with incorporation, suggesting that $\mathrm{N}$ stress was simulated where the high $\mathrm{C}: \mathrm{N}$ ratio sorghum residues $(68: 1)$ were incorporated. In contrast, the observed HI's suggested the reverse, 0.31 with removal and 0.36 with incorporation of sorghum residues, but this difference was not statistically significant.

\subsubsection{Sorghum $N$ uptake}

The observed and simulated $\mathrm{N}$ uptake in the first phase sorghum crops in the 2003/2004 and 2004/2005 seasons, for incorporated and removed residue treatments is shown in Fig. 8. There is much more scatter in the sorghum uptake predictions compared to that simulated for the legume phase crops (Fig. 5). 


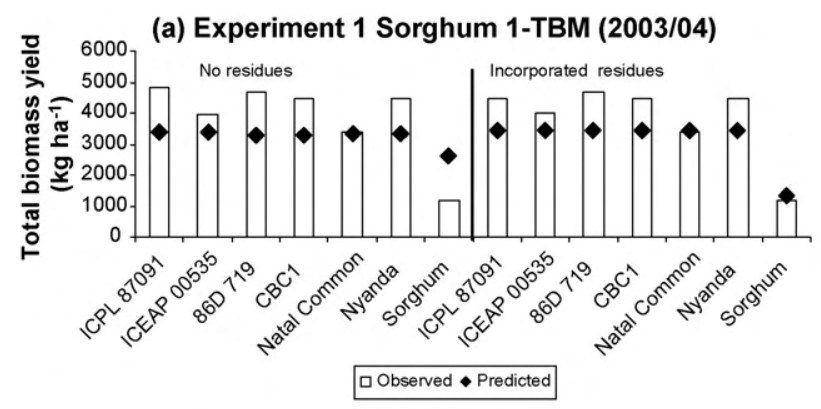

(b) Experiment 2 Sorghum 1-TBM (2004/05)

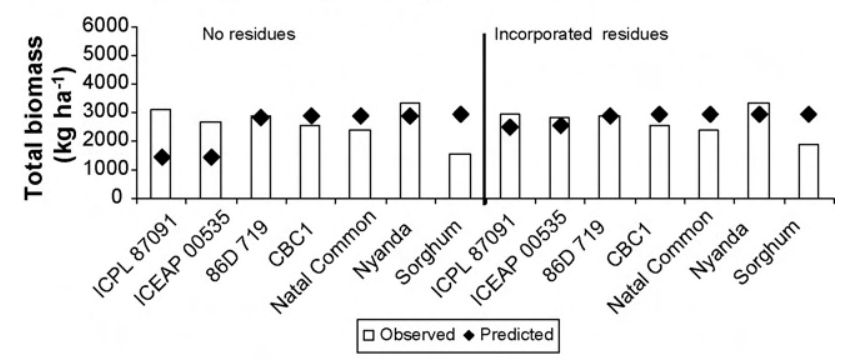

(c) Experiment 1 Sorghum 1 Grain (2003/04)

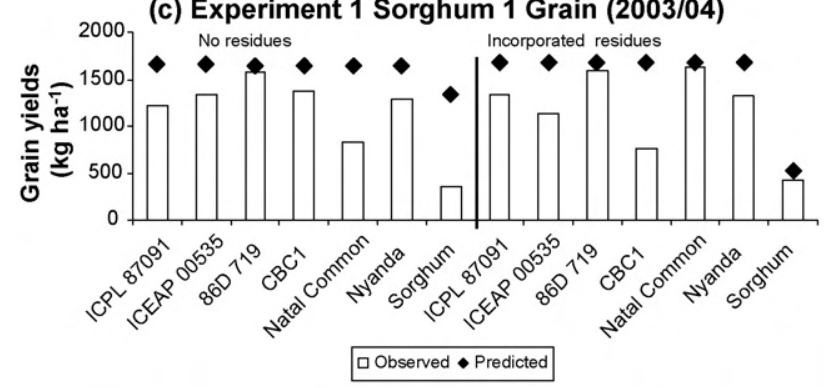

(d) Experiment 2 Sorghum 1 Grain (2004/05)

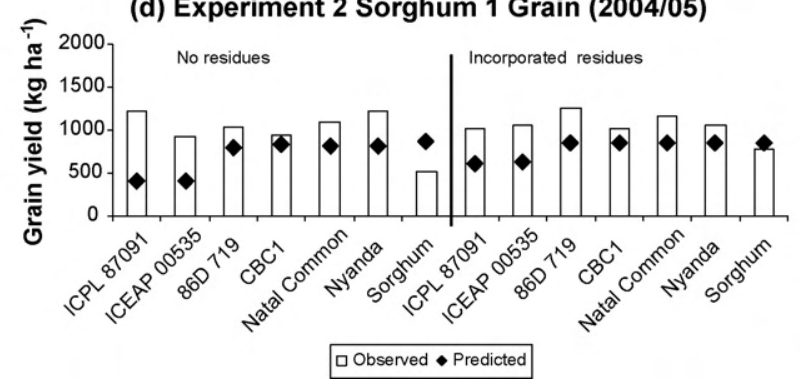

Fig. 7. Predicted and observed total biomass (a and b) and grain yield ( $c$ and d) for sorghum crops grown in rotation following pigeonpea (ICPL 87091 and ICEAP 00535), cowpea (CBC1 and 86D 719), groundnut (Natal Common and Nyanda) and sorghum over two seasons at Lucydale. RMSD values for total biomass yield were $1084 \mathrm{~kg} \mathrm{ha}^{-1}$ (no residues), $808 \mathrm{~kg} \mathrm{ha}^{-1}$ (+residues) in 2003/2004, and $817 \mathrm{~kg} \mathrm{ha}^{-1}$ (no residues), $537 \mathrm{~kg} \mathrm{ha}^{-1}$ (+residues) in 2004/2005. RMSD values for grain yield were $566 \mathrm{~kg} \mathrm{ha}^{-1}$ (no residues), $464 \mathrm{~kg} \mathrm{ha}^{-1}$ (+residues) in 2003/2004, and $336 \mathrm{~kg} \mathrm{ha}^{-1}$ (no residues), $303 \mathrm{~kg} \mathrm{ha}^{-1}$ (+residues) in 2004/2005.

Measured $\mathrm{N}$ uptake by sorghum showed little difference between plots with and without residues, whereas the model simulated much higher $\mathrm{N}$ uptake where legume residues were incorporated. Also, prediction of $\mathrm{N}$ uptake by sorghum after sorghum was more variable compared to the close predictions achieved for sorghum crops in the legume phase (see Fig. 5). Simulated $\mathrm{N}$ uptake suggests that the $\mathrm{N}$ in the legume residues was readily available, but that the additional $\mathrm{N}$ supply had no effect on simulated TBM or grain yield responses in the two seasons

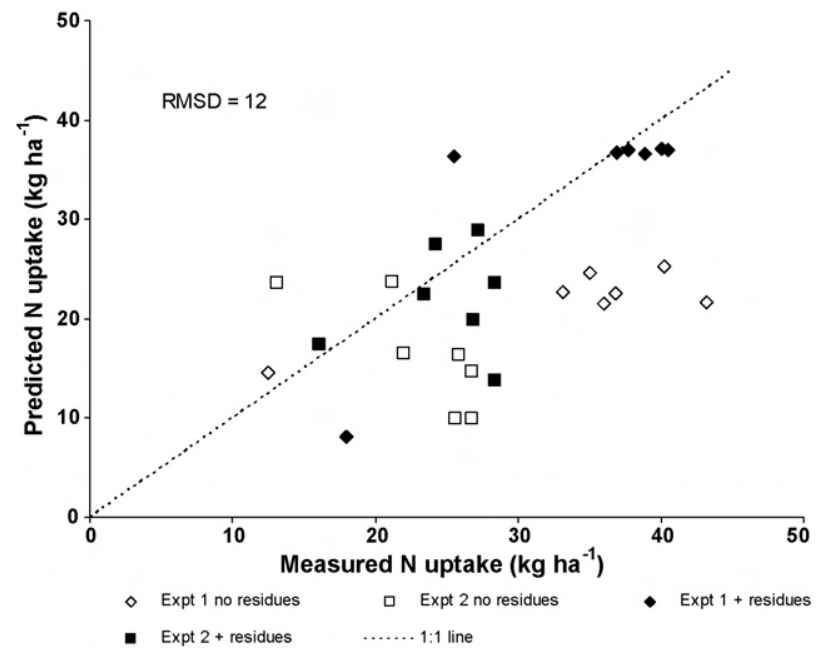

Fig. 8. Plot of predicted against observed sorghum nitrogen uptake at Lucydale over two cropping seasons $(2003 / 2004$ and $2004 / 2005) . R^{2}$ : no residues $=0.15, R^{2}$. + residues $=0.63$.

(Fig. 7). One explanation for the lack of response to legume residue incorporation in 2003/2004 is that the below-ground changes in soil organic $\mathrm{N}$ supply brought about by the legume crops was sufficient to meet the needs of sorghum growth, and that these soil changes were adequately captured in the model through additions of legume root material and spared $\mathrm{N}$ effects. At the same time, however, the over-prediction of $\mathrm{N}$ uptake by the model may be the result of under-predicting $\mathrm{NO}_{3}$ leaching in the high rainfall season.

(a) Experiment 1 Sorghum 2-TBM (2004/05)

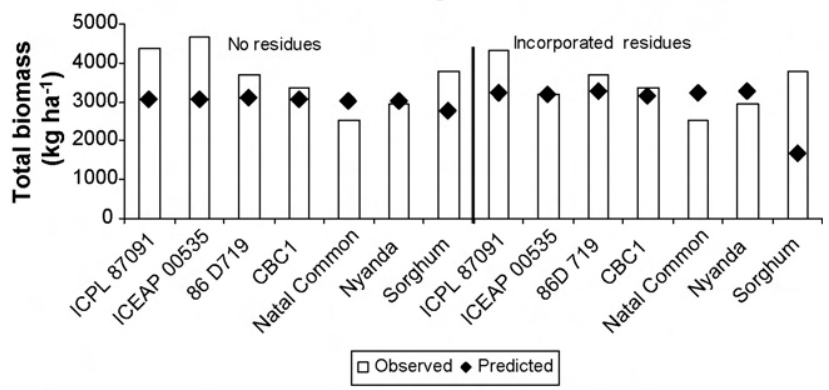

(b) Experiment 1 Sorghum 2-Grain (2004/05)

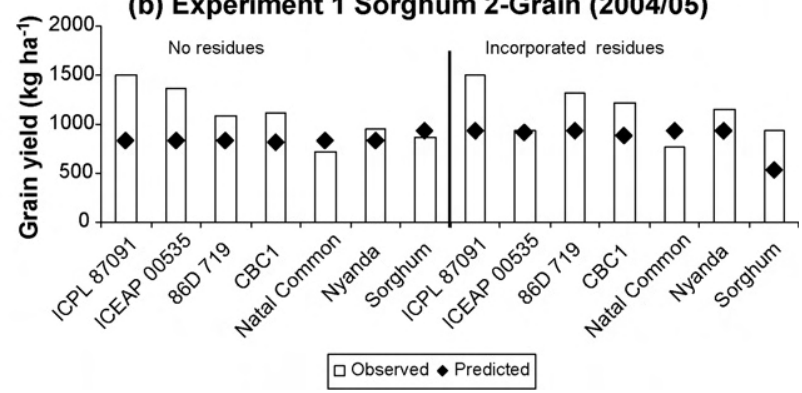

Fig. 9. Predicted and observed second rotation sorghum total biomass and grain yields following pigeonpea (ICPL 87091 and ICEAP 00535), cowpea (CBC1 and 86D 719), groundnut (Natal Common and Nyanda) and sorghum over two seasons at Lucydale. The error bars represent standard errors of difference between means of the previous legume variety and residues. RMSD values for total biomass yield were $848 \mathrm{~kg} \mathrm{ha}^{-1}$ (no residues) and $943 \mathrm{~kg} \mathrm{ha}^{-1}$ (+residues). RMSD values for grain yield were $283 \mathrm{~kg} \mathrm{ha}^{-1}$ (no residues) and $287 \mathrm{~kg} \mathrm{ha}^{-1}$ (+residues). 
(a) $\mathrm{N}$ stress in the rotation - residues removed

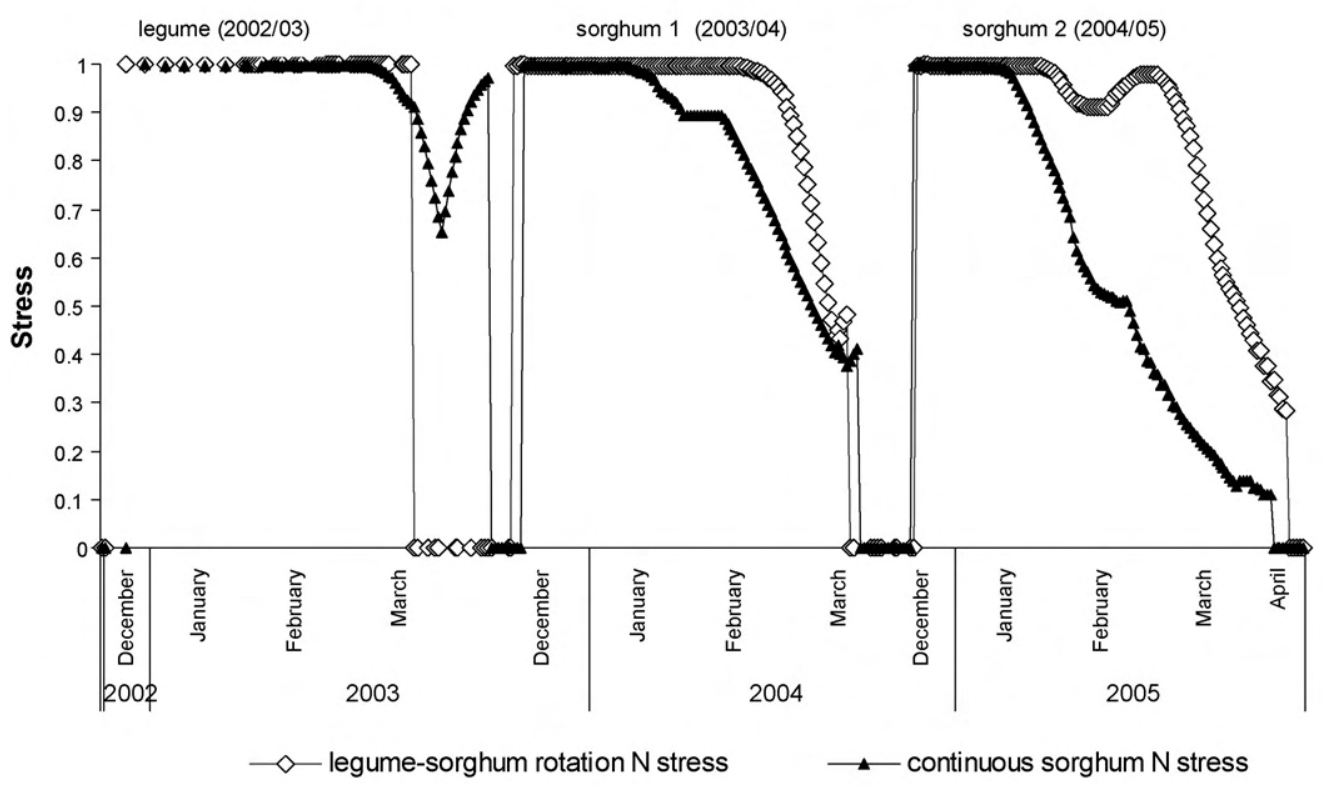

(b) Water stress in the rotation - residues removed

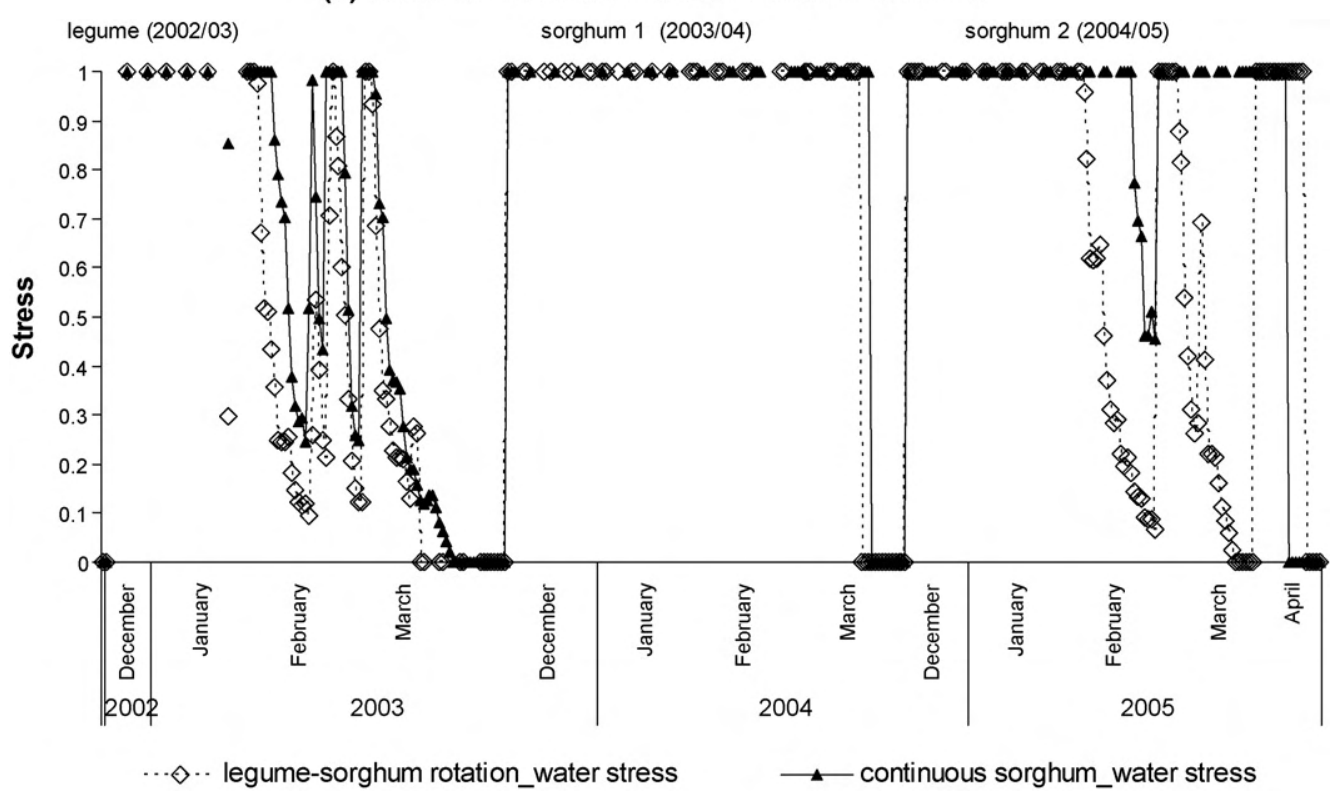

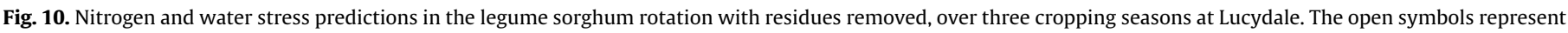

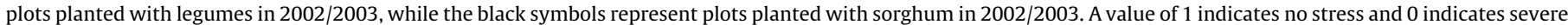
stress.

\subsubsection{Simulation of the second sorghum rotation}

The model predicted the total biomass and grain yield of the second sorghum after legumes close to the observed yields in plots that had been planted with cowpeas and groundnuts in the 2002/ 2003 season (Fig. 9). However, the model generally underpredicted grain and total biomass of sorghum in the plots previously planted with pigeonpea or which had sorghum residues incorporated.

The under-prediction of sorghum yields after pigeonpea can be explained by the failure to account for leaf fall in the model. The under-prediction of sorghum yield after sorghum residue incorporation reflects continuing effects of simulated $\mathrm{N}$ immobilisation, whereas observed yields suggest a higher availability of $\mathrm{N}$ in the soil.

\subsection{Simulation of nitrogen and water stress in the rotation}

Analysis of the simulated stress factors on crop growth showed interesting results: the nitrogen and water stress predictions in Experiment 1 across the three cropping seasons are shown under situations with both residue removal (Fig. 10) and residue incorporation (Fig. 11). The APSIM model describes plant stress on a $0-1$ scale; at values of 1 there is no stress on crop growth or development, and at 0 these processes are halted completely. 
(a) $\mathrm{N}$ stress in the rotation - residues incorporated

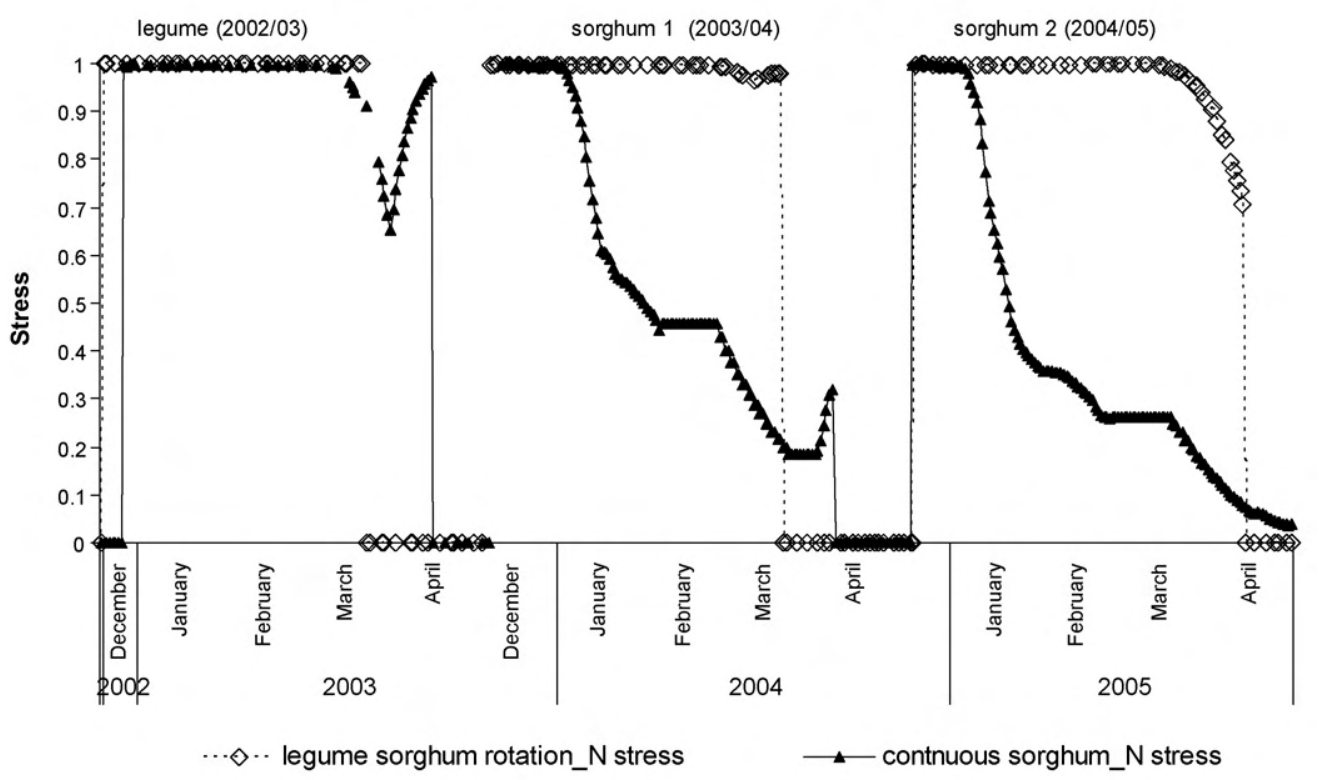

(b) Water stress in the rotation - residues incorporated

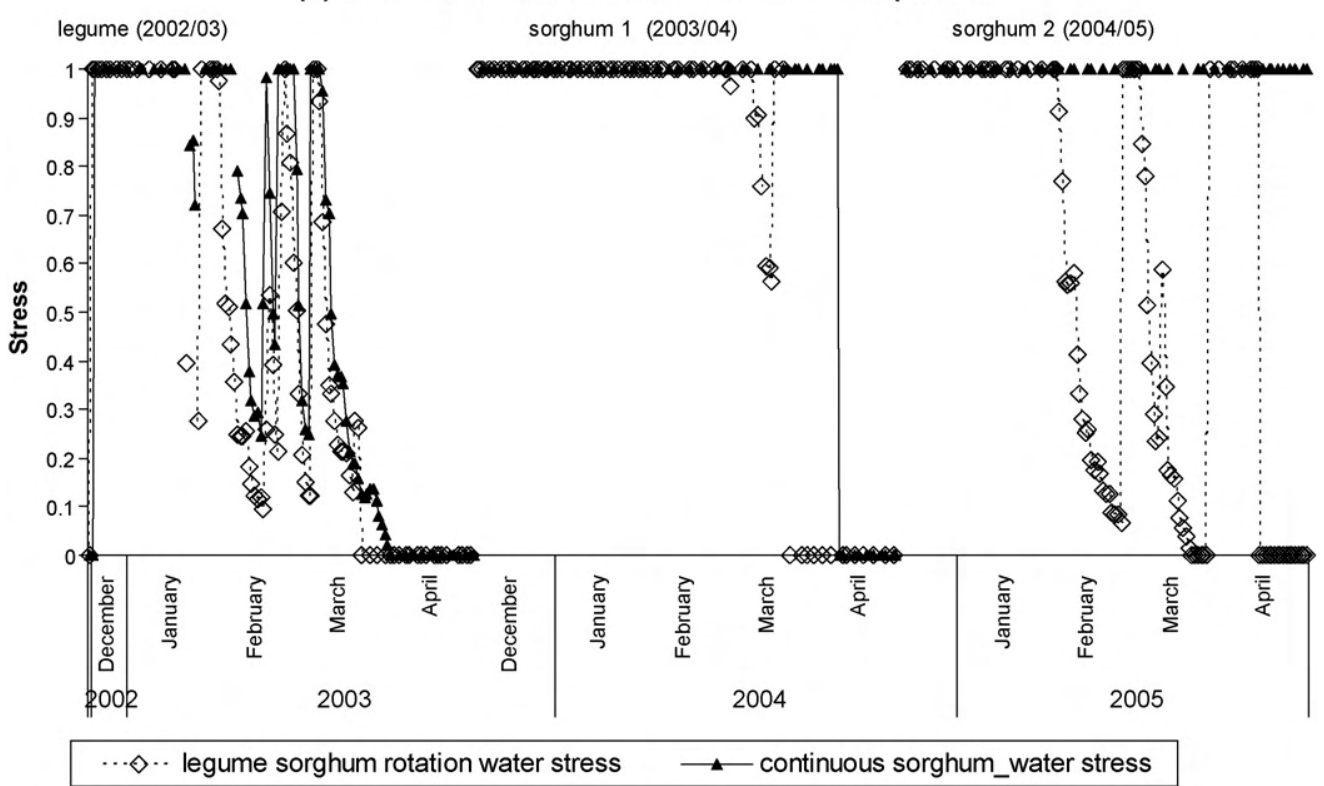

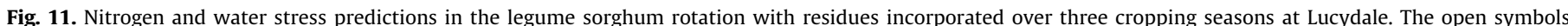

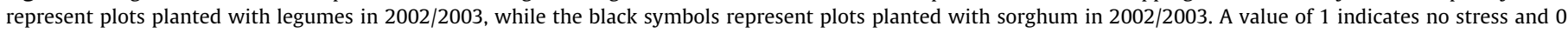
indicates severe stress.

In the first season of planting (legume phase) only the sorghum crop showed slight (0.6) $\mathrm{N}$ stress towards the end of the season (Figs. 10a and 11a (legume 2002/2003)), whereas both legume and sorghum crops experienced episodes of water stress from 30 days after sowing until the end of the season (Figs. 10b and 11b). In the wet 2003/2004 season, no moisture stress was simulated for the legume-sorghum or the sorghum-sorghum treatments except briefly in the dry February/March period where legume residues had been incorporated and the higher $\mathrm{N}$ supply presumably resulted in higher crop growth and water demand (Fig. 11b, 2003/ 2004). Accordingly, the model simulated no N stress during crop growth in the legume-sorghum treatment where residues had been incorporated (Fig. 11a, 2003/2004). Where legume residues had been removed, $\mathrm{N}$ stress was simulated late in the sorghum crop and rapidly approached the $\mathrm{N}$ stress levels simulated for sorghum-sorghum treatment, which had experienced $\mathrm{N}$ stress much earlier in the season and approached 0.4 at crop harvest (Fig. 10a, 2003/2004). Where sorghum residues were incorporated, the simulated $\mathrm{N}$ stress was much more severe, approaching 0.5 at about flowering and 0.2 at harvest (Fig. 11a, 2003/2004).

In the dry 2004/2005 season, severe $\mathrm{N}$ stress was simulated for the continuous sorghum plots, with the degree of stress continuing to be more extreme where sorghum residues had been incorporated in the 2002/2003 season (Fig. 11a, 2004/2005). Significantly, 
no moisture stress was simulated in the continuous sorghum plots in this dry season, except for a brief period in the no residue plots (Fig. 10b, 2004/2005). In contrast, very strong moisture stress was simulated in the legume-sorghum plots, with or without incorporated legume residues. The simulated $\mathrm{N}$ stress in the legume-sorghum plots in 2004/05 was delayed appreciably compared with the sorghum-sorghum treatment, but was more severe where legume residues had been removed (0.3) compared with incorporated (0.7).

The model output of $\mathrm{N}$ and water stress factors on plant growth is instructive in better understanding the water, $\mathrm{N}$ and plant growth interactions within a cropping season, as well as the residual benefits of legumes interacting with variable seasonal conditions. The model results suggest that the productivity of a legume phase in this environment can overcome the $\mathrm{N}$ supply deficits of the low carbon soils for sorghum production in southwestern Zimbabwe for up to two seasons of sorghum production. Importantly, it (and the experimental results) shows that this can be largely achieved even if the legume stover is removed and used for other purposes such as animal feed. However, the trade-off in this low rainfall environment is that by removing the $\mathrm{N}$ constraint, the sorghum crops are much more likely to experience increased water stress. Alternatively, if the $\mathrm{N}$ constraint is not removed, than the $\mathrm{N}$ stress will greatly limit the use of available moisture, even in a very dry season such as 2004/2005.

\section{Conclusions}

The main objectives of modelling the Lucydale results were to assess how the APSIM model could assist in explaining the mechanism of the residual benefits of legumes to sorghum under semi-arid conditions. Many crop-soil models have been developed but most of them look at single crops and they lack the capacity to deal with crop sequences. This paper is an example of work that tries to demonstrate the capacity of APSIM to analyse the impacts of legumes on the following cereal under semi-arid conditions. The results of the study showed that APSIM is capable of predicting legume and sorghum yields under semi-arid conditions in southern Africa. The model gave satisfactory predictions of legume yields across the three cropping seasons, and also gave reasonable predictions of the yields of sorghum grown in the rotation. There is need to further calibrate the model crop parameters for legumes such as pigeonpea and groundnut. The APSIM model also gave insight into the dynamics of nitrogen and water in the rotations by showing that the residual benefits of legumes to subsequent sorghum were mainly due to nitrogen, rather than water under these semi-arid conditions. Further testing of the model will assist in understanding the role of processes such as $\mathrm{N}$ mineralisation of crop residues in the legume-cereal rotations.

\section{Acknowledgements}

The authors are grateful to the Netherlands Foundation for Science in the Tropics (WOTRO) and the International Crops Research Institute for the Semi-Arid Tropics (ICRISAT) for funding the research.

\section{References}

Armstrong, R.D., McCosker, K., Millar, G., Kuskopf, B., Johnson, S., Walsh, K., Probert M.E., Standley, J., 1999. Legume and opportunity cropping systems in centra Queensland. 2. Effect of legumes on following crops. Aust. J. Agric. Res. 50, 925936.

Bell, J.P., 1987. Neutron Probe Practice. Report No. 19, third edition. Institute of Hydrology, Wallingford, England, pp. 51.
Boddey, R.M., Peoples, M.B., Palmer, B., Dart, P.J., 2000. Use of the N-15 natural abundance technique to quantify biological nitrogen fixation by woody perennials. Nut. Cycl. Agroecosyt. 57, 235-270.

Delve, R.J., Probert, M.E., 2004. Modelling nutrient management in tropical cropping systems. Australian Centre for International Agricultural Research (ACIAR). Centro Internacional de Agricultura Tropical (CIAT), Canberra, AT, ACIAR proceedings no. 114. pp. 135-138.

Dimes, J., Malherbe, J., 2006. Climate variability and simulation modelling-challenges and opportunities, In: Mgonja, M.A., Waddington, S., Rollin, D. Masenya, M. (Eds.), Livelihoods in the Limpopo: CGIAR Challenge Program on Water and Food Project No 1. (CPWFPN1): Increased Food Security and Income in the Limpopo Basin through Intergrated Crops, Soil Fertility and Water Management Options and Links to Markets. Proceedings of the CPWFPN1 Inception Workshop, January 25-27, 2005. ICRISAT, Polokwane, South Africa, Bulawayo, Zimbabwe. 132 pp.

Dimes, J., Muza, L., Malunga, G., Snapp, S., 2002. Trade-offs between investments in nitrogen and weeding: on-farm experimentation and simulation analysis in Malawi and Zimbabwe. In: Friesen, D.K., Palmer, A.F.E. (Eds.), Intergrated Approaches to Higher Maize Productivity in the New Millenium: Proceedings of Seventh Eastern and Southern Africa Regional Maize Conference, February 511 2002. CIMMYT (International Maize and Wheat Improvement Center) and KARI (Kenya Agricultural Research Institute), Nairobi, Kenya.

Giller, K.E., 2001. Nitrogen Fixation in Tropical Cropping Systems. CAB International, Wallingford, UK.

Hammer, G.L., van Oosterom, E.J., Chapman, S.C., McLean, G., 2001. The economic theory of water and nitrogen dynamics and management in field crops. In: Borrell, A.K., and Henzel, R.G. (Eds.), Proceedings Fourth Australian Sorghum Conference, Kooralbyn, Qld. February 5-8 2001. CD ROM Format. Range Media Pty Ltd. ISBN: 0-7242-2163-8.

Hilderbrand, G.L. 1996. The status of technologies used to achieve high groundnut yields in Zimbabwe. In: Gowda, G.L.L., Nigam, S.N., Johansen, C., Renard, C. (Eds.), Achieving high groundnut yields: Proceedings of an International Workshop, 25-29 1995. Laixi City, Shandong, China (in En summaries in En, Ch.). International Crops Research Institute for the Semi Arid Tropics, Patancheru, Andra Pradesh, India. 300 pp. ISBN 92-9066-350-2. Order Code CPE 105.

Hill, J.O., Robertson, M.J., Pengelly, B.C., Whitbread, A.M., Hall, C.A., 2006. Simulation modelling of lablab (Lablab purpureus) pastures in northern Australia. Aust J. Agric. Res. 57, 389-401.

Keating, B.A., Carberry, P.S., Hammer, G.L., Probert, M.E., Robertson, M.J., Holzworth, D., Huth, N.I., Hargreaves, J.N.G., Meinke, H., Hochman, Z., McLean, G., Verburg, K., Snow, V., Dimes, J.P., Silburn, M., Wang, E., Brown, S., Bristow, K.L., Asseng, S., Chapman, S., McCown, R.L., Freebairn, D.M., Smith, C.J., 2003. An overview of APSIM, a model designed for farming systems simulation. Eur. J. Agron. 18, 267288.

Keating, B.A., Carberry, P.S., Robertson, M.J., 1999. Simulating N fertiliser responses in low-input farming systems. 2. Effects of weed competition. In: Donatelli, M., Stockle, C., Villalobus, F., Villar Mir, J.M. (Eds.), International Symposium, Modelling Cropping Systems, Proceedings European Soc. For Agronomy, Div. Agroclimatology and Agronomic Modelling, Lleida, Spain, June 21-23 1999. pp. 205-206.

Kobayashi, K., Salam, M.U., 2000. Comparing simulated and measured values using mean squared deviation and its components. Agron. J. 92, 345-352.

McCown, R.L., Hammer, G.L., Hargreaves, J.N.G., Holzworth, D.P., Freebairn, D.M., 1996. APSIM: a novel software system for model development, model testing, and simulation in agricultural research. Agric. Syst. 50, 255-271.

Mapfumo, P., Giller, K.E., 2001. Soil Fertility Management Strategies and Practices by Smallholder Farmers in Semi-arid Areas of Zimbabwe. International Crops Research Institute for the Semi Arid Tropics (ICRISAT) with permission from the Food and Agricultural Organization (FAO), Bulawayo, Zimbabwe and Rome, Italy, p. 60.

Ncube, B., Twomlow, S.J., van Wijk, M.T., Dimes, J.P., Giller, K.E., 2007. Productivity and residual benefits of grain legumes to sorghum under semi-arid conditions in south-western Zimbabwe. Plant Soil 299 (1-2), 1-15.

Probert, M.E., Carberry, P.S., McCown, R.L., Turpin, J.E., 1998. Simulation of legumecereal systems using APSIM. Aust. J. Agric. Res. 49, 317-327.

Probert, M.E., Delve, R.J., Kimani, S.K., Dimes, J.P., 2005. Modelling nitrogen mineralization from manures: representing quality aspects by varying C:N ratio of sub-pools. Soil Biol. Biochem. 37, 279-287.

Ritchie, J.T., 1972. Model for predicting evaporation from a row crop with incomplete cover. Water Resour. Res. 8, 1204-1213.

Robertson, M.J., Carberry, P.S., Chauhan, Y.S., Ranganathan, R., O'Leary, G.J., 2001. Predicting growth and development of pigeonpea: a simulation model. Field Crops Res. 71, 195-210.

Robertson, M.J., Carberry, P.S., Huth, N.I., Turpin, J.E., Probert, M.E., Poulton, P.L., Bell, M., Wright, G.C., Yeates, S.J., Brinsmead, R.B., 2002. Simulation of growth and development of diverse legume species in APSIM. Aust. J. Agric. Res. 53, 429-446.

Robertson, M.J., Sakala, W., Benson, T., Shamudzarira, Z., 2005. Simulating response of maize to previous velvet bean (Mucuna pruriens) crop and nitrogen fertiliser in Malawi. Field Crops Res. 91, 91-105.

Rowe, E., Giller, K.E., 2003. Legumes for soil fertility in southern Africa: needs, potential and realities. In: Waddington, S.R. (Ed.), Grain Legumes and Green Manures for Soil Fertility in Southern Africa: Taking Stock of Progress. Soil Fert Net-CIMMYT, Harare, Zimbabwe. pp. 15-19.

Sanginga, N., 2003. Role of biological nitrogen fixation in legume based cropping systems; a case study of West Africa farming systems. Plant Soil 252, 25-39. 
Shamudzarira, Z., Robertson, M.J., 2002. Simulating the response of maize to nitrogen fertiliser in semi-arid Zimbabwe. Exp. Agric. 38, 79-96.

Tsuji, G.Y., Uehara, G., Balas, S. (Eds.), 1994. DSSAT 3.. University of Hawaii, Honolulu, Hawaii.

Twomlow, S.J., 2004. Increasing the role of legumes in smallholder farming systems-the future challenge. In: Serraj, R. (Ed.), Symbiotic Nitrogen Fixation: Prospects for Application in Tropical Agroecosystems. Science Publishers, NH, USA, pp. 29-46.

van Keulen, H., Seligman, N.G., 1987. Simulation of water use, nitrogen nutrition and growth of a spring wheat crop. Simulation Monograph, Pudoc Wageningen, The Netherlands.

Whitbread, A., Braun, A., Alumira, J., Rusike, J., 2004. Using the agricultural simulation model APSIM with smallholder farmers in Zimbabwe to improve farming practices. In: Whitbread, A., Pengelly, B.C. (Eds.), Tropical Legumes for Sustainable Farming Systems in Southern Africa and Australia. Australian Centre for International Agricultural Research, Canberra, ACIAR Proceedings No. 115. pp. 171-80.

Whitbread, A.M., Clem, R.L., 2006. Graze to grain-measuring and modelling the effects of grazed pasture leys on soil nitrogen and sorghum yield on a Vertisol soil in the Australian subtropics. Aust. J. Agric. Res. 57, 489-500.

Williams, J.R., LaSeur, W.V., 1976. Water yield model using SCS curve numbers. J. Hydraul. Div. Am. Soc. Civil Eng. 102 (HY9), 1241-1253.

Williams, J.R., Dyke, P.T., Fuchs, W.W., Benson, V. W., Rice, D.W. Taylor, E.D., 1990. EPIC: Erosion/Productivity Impact Calculator. 2. User Manual. United States Department of Agriculture Technical Bulletin No. 1768, Washington, DC, 127 p. 